\title{
Using the Technology-Organization-Environment Framework Approach in the Acceptance of Telemedicine in the Health Care Industry
}

\author{
Sukardi, Hasyim, and Supriyantoro
}

\section{ABSTRACT}

Telemedicine is an innovation in providing health services to patients, perceptions of technology vary from one individual to another. The level of technology acceptance is something that needs to be researched because it will affect the use of a technology in the company, this is because the received technology will continue to be used in the company and the rejected technology will be a neglected part. There are the important considered criteria for the acceptance of a technology of this research: the adoption of innovation, organizational measurement, business environment, and communication channels.

The purpose of this study was to analyze the effect of technology acceptance, organizational size, business environment on the adoption of telemedicine with the influence of the communication channel. The research method is an explanatory research using a quantitative approach. The population in this study was 156 people. The used data analysis method in this research is a Moderated Regression Analysis (MRA). The results from the MRA analysis show that technology acceptance is positively and significantly influenced by communication channels on the adoption of telemedicine. In contrast, the measurement of the organization and the business environment did not have a significant effect on the adoption of telemedicine in the health service industry. The implication of hospital management to increase technology acceptance must pay attention to the advantages of using telemedicine, the suitability of existing technology in hospitals to develop telemedicine, the ease of used technology, the results that seen from the use of telemedicine and it can be tested before being applied. Communication needs to be improved by paying attention to the credibility of the communicator, the content and context of telemedicine, the clarity and continuity of information, the used language is easy to understand and the right communication channel is interpersonal.

Keywords: Diffusion of Telemedicine Innovation, Technology-OrganizationEnvironment, Communication.

\author{
Submitted : March 31, 2021 \\ Published : May 06, 2021 \\ ISSN: 2507-1076 \\ DOI: $10.24018 /$ ejbmr.2021.6.3.837 \\ Sukardi * \\ Master of Hospital Administration \\ Programme, Esa Unggul University, \\ Jakarta, Indonesia. \\ (e-mail: dreddysukardi@ gmail.com) \\ Hasyim \\ Master of Hospital Administration \\ Programme, Esa Unggul University, \\ Jakarta, Indonesia. \\ (e-mail: hasyim.ahmad@esaunggul.ac.id) \\ Supriyantoro \\ Master of Hospital Administration \\ Programme, Esa Unggul University, \\ Jakarta, Indonesia. \\ (e-mail: priyantoro11@gmail.com) \\ *Corresponding Author
}

\section{INTRODUCTION}

Telemedicine is the provision of long-distance health services [1]. Telemedicine is a health service that is carried out remotely through the media of information technology and telecommunications. According to telemedicine can expand the scope of doctors to be able to treat patients who are not limited by distance [2].

Not all of health facilities are ready to welcome the era of disruption 4.0 which is full of digitization. Various obstacles related to human resources, funding sources, business processes, government regulations, and the lack of integration of the system are challenges in realizing this.

Perceptions of technology vary from one individual to another. Perceptions of technology originate from cognitive processes and beliefs about technology. Telemedicine is an innovation in providing services to patients. Through the book Diffusion of innovation, Rogers [3] explains the concept of diffusion of innovation and the speed at which a social system accepts new ideas offered by an innovation. The user's intention of technology by using the Technology Acceptance Model (TAM) model. The application of telemedicine at the PPKM-SMEC is a new computerized system and is different from the previous system between the doctor-patient relationships. Therefore, the use of telemdis needs to be analyzed whether the new system can be used properly and is useful or rejected so that it becomes a neglected technology.

The Eye Health Service Center (PPKM) SMEC which consists of several hospitals and special eye clinics, SMEC stands for Sabang Merauke Eye Center which was first established on March 4, 2006 as a class C private hospital in the city of Medan, and until recently 33 branches throughout Indonesia. PPKM SMEC has a vision which reads "To become the leading, most modern, and professional eye health service center in Indonesia so that it can compete with similar institutions abroad". And the mission which reads "to provide quality eye health services with highly qualified medical equipment and competent and professional human resources, oriented to patient needs and satisfaction at affordable costs and managed with a management pattern that implements continuous quality improvement in every 
element of services. With the motto "Keep Your Eyes Healthy".

PPKM SMEC developed telemedicine in October 2019, which is between the Pratama Sakinah clinic Pekanbaru and SMEC Jakarta. The general practitioner at the Sakinah clinic conducted a teleconsultation in the form of a video conference and sent the diagnostic examination results to an ophthalmologist at SMEC Jakarta. In 2020, PPKM SMEC will develop the SMEC Virtual Care service, which is implemented in all branches, however the existing telemedicine does not work operational.

Theoretically, technology adoption is a mental process or behavior change in the form of knowledge, attitudes, skills in a person from the time he recognizes innovation until he decides to adopt it after receiving innovation [3]

Diffusion of Innovation consists of two equivalent words, diffusion, and innovation. Everett M. Rogers in the book diffusion of innovation [3] defines Diffusion as a process where an innovation is communicated through certain channels within a certain period of time among members of a social system, it is considered as a type of social change, a process of change that occurs in the structure and function of the social system.

Rogers [3] mentions innovation as an idea, practice, or thing that is considered / felt new by individuals or groups of people. Expressions are considered new to an idea, practice, or thing by some people, not necessarily to others. It all depends on how the individual or group feels about the idea, practice, or object. Ideas that are perceived as new by the individual determine the reaction to them [3].

Rogers [3] argues there are five attributes of technology: relative advantage, suitability, complexity, testable, observable. The communication channel is how the message is obtained by an individual from another individual [3]. Communication is a process where participants create and share information with each other to achieve a common understanding.

Rogers [3] suggests that the theory of innovation decisions begins with knowledge, persuasion, decisions, implementation, and confirmation. The most important stage is persuasion because at this stage the individual is interested in innovation and is actively seeking detailed information about the innovation, in this second stage it is more at the level of thought of the potential user [3].

Rogers [3] also explains that there are five adopter groups in the social system, consisting of: $2.5 \%$ are innovators (groups of people who are brave and ready to try new things), $13.5 \%$ are early adopters (groups that generate more opinions and are always looking for information. about innovation), $34 \%$ early majority (a group that is careful before making a decision to adopt an innovation, that it is a long time until they show that the investment is useful and feasible to use), $34 \%$ late majority (This group is careful about the functions an innovation, waiting for everyone to adopt an innovation), $16 \%$ laggards (this group is the last person to adopt an innovation, is more traditional and is reluctant to try new things) [3].

The TOE (Technology-Organization-Environment) model was developed to identify the dominant factors that influence the technology adoption process and its implementation [7].
Tornatzky and Fleischer [7] emphasized that technology is a tool containing knowledge, a mixture of social / behavioral elements and physical elements. Technology itself is only a physical tool but involves knowledge because the user must interact with technology to find out the purpose of its use, how to operate the tool and the impact of its use [7].

Organization according to Senge [8] is where people continuously develop their capacities to create the results they really want, where new and developing thinking patterns are fostered, group aspirations are given freedom, and people continuously (learning to learn) something together [8].

Finally, in the context of the TOE model environment, it explains that to adopt new technology, an organization must interact with the surrounding business environment. The business environment refers to the entities that exist in their industry namely customers, suppliers, competitors, government officials, regulatory bodies, and other external factors. The environmental context is the arena in which the company does business, including the industry in which the company operates, competitors, and the government [7]. Several dimensions of the business environment are competitive pressure and trading partner support [9] Environment by Duncan (1972) is defined as the totality of social and physical factors that influence a person's decisionmaking behavior in the organization [9].

TOE framework according to Oliviera and Martins [10] provides a research model that has a strong theoretical basis and can be used in various types of research on innovation adoption.

Yeo et al. (2017) examined the perceptions of healthcare providers in Malaysia towards telecardiology which was developed to reduce waiting times and reduce traveling patients. Yeo found obstacles in the adoption of telemdicine such as the ease of technology, the need for user training, ease of use, and doctors prefer face-to-face consultations, as well as large costs to build telemedicine. [14]

Martin et al. (2019) conducted a survey of 223 Spanish analogy doctors to analyze the factors that influence doctors' interest in using teledermatology. The results showed that the factors that most influenced the use of teledermatology were technology specifications, system efficiency, and the influence of others. [15]

In a previous study using the diffusion concept of innovation conducted by Hasym et al (2017) entitled developing conceptual model for online shopping attitude in Indonesia. The results of his research indicate that the level of innovation, the level of technology acceptance, and trust have a positive effect on online shoppers' attitudes.[16]

The integration of TAM and the diffusion of innovation models in the use of e-learning systems has also been studied by Al-Rahmi et al (2019) showing that the relationship between relative adventage, observability, trialability, perceived compatibility, complexity, and perceived enjoyment has a strong influence on perceived usefulness and perceived ease of use [4].

Previous research using TAM and diffusion of innovation has had a positive influence on the innovation factor on technology adoption [5].

The interest in telemedicine has also been studied by Kissi et al [6] entitled Predictive factor of physicians' satisfaction with telemedicine service acceptance. The results of this 
study indicate that perceived usefulness and perceived ease of use affect doctors' behavioral intention to use telemedicine. Efficiency, quality, service to patients, and user satisfaction influence doctors to use telemedicine.

Researchers conducted a preliminary study from the results of a preliminary survey in ten PPKM SMEC branches, it was found that $50 \%$ did not know telemedicine, $70 \%$ did not understand the technology used for telemedicine, $80 \%$ did not know management support for telemedicine. $70 \%$ of branch heads and center heads do not know the exact technicality of the implementation of telemedicine. The implementation of telemedicine at PPKM SMEC has experienced several problems including:

1) The percentage of groups that are included in the late adopter and laggard categories is still high, causing low acceptance of innovation.

2) the level of acceptance of ophthalmologists towards telemedicine is still insufficient because the results of telemedicine examinations are still doubtful.

3) Telemedicine requires a lot of money and facilities that are not fully supported.

4) Lack of communication between central management and all branches and centers of PPKM SMEC.

5) Organizational culture and management of health services are still traditional, interactions between doctors and patients still have to come face to face to provide health services.

6) A business environment that has a competitive level in pandemic conditions.

Researchers want to know more about the factors that influence the adoption of telemedicine in PPKM SMEC using the TOE framework approach with communication as a moderating variable. The aim and contribution of the research are expected to provide input for PPKM SMEC in order to provide information on what factors have an influence on telemedicine adoption so as to improve telemedicine implementation in all branches. For educational institutions, this research can be used as initial data for further research and a source of comparative reading for telemedicine adoption. And for researchers, this research is expected to add insight into the adoption of telemedicine innovation with the TOE framework approach in PPKM SMEC.

\section{METHOD}

This research is an explanatory research using a quantitative approach which aims to explain the causal relationship between the variables studied.

The population in this study was 156 people. The sample size in this study was calculated using the Slovin formula and determined to be 125 people. Data were collected using a questionnaire in google form.

Data analysis using Moderate Regression Analysis (MRA). This research has received information that has passed the ethical review of the Esa Unggul University Research Ethics Commission in an effort to protect the human rights and welfare of the subject, no. 0345-20.334 / DPKE-KEP / FINAL-EA / UEU / IX / 2020.

\section{A. Variable Measurement}

This research was conducted to explain the relationship of three variables, namely the independent variables which include: technology acceptance (X1), Organization Size (X2), Business Environment (X3) with the dependent variable, namely the adoption of telemedicine (Y) and the communication channel as a moderating variable $(\mathrm{Z})$. The type of research used is associative quantitative because the researcher wants to know whether there is a relationship between the variables through testing the hypothesis that has been formulated.

Telemedicine adoption variables have the following dimensions:

1. Positive perception;

2. Interests and Motivation;

3. Recommendation;

4. Intensity.

The acceptance variable of technology has dimensions:

1. Relative advantage;

2. Compatibility;

3. Complexity;

4. Trialability;

5. Observability.

The variable of organizational measurement has dimensions:

1. Organization competency;

2. Top management support;

3. Training and education.

The variable of business environment has dimensions:

1. Competitive pressure;

2. Market turbulance;

3. Regulation.

The variable of communication channel has dimensions:

1. Credibility;

2. Context;

3. Content;

4. Clarity;

5. Continuity;

6. Capability of audiens;

7. Communication type.

The measurement scale in this study uses a Likert scale 14 with 1 (strongly disagree) to 4 (strongly agree).

The relationship between research variables is described in the following constellation:

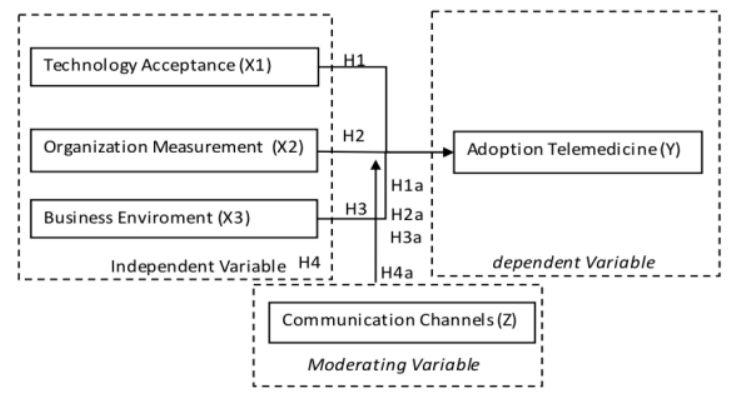

Fig. 1. Research Constellation.

\section{B. Research Hypothesis}

Based on the research constellation, the hypotheses of this study are as follows: 
H1: Technology acceptance has a positive effect on telemedicine adoption at PPKM-SMEC.

H1a: The communication channel moderates the role of technology in the adoption of telemedicine in PPKM SMEC.

$\mathrm{H} 2$ : Organizational measurement has a positive effect on telemedicine adoption in PPKM-SMEC.

H2a: The communication channel moderates the role of organizational measurement on telemedicine adoption in PPKM SMEC.

H3: The business environment has a positive effect on telemedicine adoption in PPKM-SMEC.

H3a: The communication channel moderates the role of the environment in the adoption of telemedicine in PPKM SMEC.

H4: Technology acceptance, organization size, business environment simultaneously has a positive effect on telemedicine adoption in PPKM-SMEC.

$\mathrm{H} 4 \mathrm{a}$ : The communication channel moderates the role of technology acceptance, organization measurement, and business environment simultaneously on telemedicine adoption.

\section{RESULT}

A. Description of Respondents' Data

\begin{tabular}{lcc}
\multicolumn{2}{c}{ TABLE I: DISTRIBUTION OF RESPONDENT CHARACTERISTICS } \\
\hline Nender & $\mathrm{N}$ & Percentage \\
Male & 68 & 44.2 \\
Female & 86 & 55.8 \\
Total & 154 & 100 \\
Age & & \\
20-30 & 70 & 45.5 \\
$31-40$ & 53 & 34.4 \\
$41-50$ & 26 & 16.9 \\
$>50$ & 5 & 3.2 \\
Total & 154 & 100 \\
Education & & \\
D3 & 29 & 18.8 \\
S1 & 116 & 75.3 \\
S2 & 9 & 5.8 \\
Total & 154 & 100 \\
Profession & & \\
Ophthalmologist & 34 & 22.1 \\
Ophthalmologist Subspecialty & 14 & 9.1 \\
General practitioners & 16 & 10.4 \\
Nurse & 76 & 49.4 \\
Optical Refraction & 14 & $9.1 \%$ \\
Total & 154 & 100 \\
\hline
\end{tabular}

Based on the data above, it is known that 154 respondents who were studied based on gender, it was found that female gender was a greater proportion than male employees. Most of the respondents were in the age 20-30 (45.5\%). From 154 respondents studied based on education, it was dominated by $\mathrm{S} 1,75.3 \%$. The respondents studied based on profession, most of the nurses (49.4\%) and the total of doctors (41.6\%) consisted of ophthalmologists, eye subspecialists, and general practitioners.

\section{B. Description of Respondents' Responses}

Descriptions of respondents' answers are obtained from the total frequency of respondents in providing answers in each statement that measures the research variable. The results of the descriptive analysis recapitulation are presented as follows:
TABLE II: RESPONDENTS' RESPONSES

\begin{tabular}{|c|c|c|c|}
\hline \multirow{2}{*}{ No } & \multirow{2}{*}{ Variable } & \multicolumn{2}{|c|}{ Position of Respondent's Response } \\
\hline & & Height & Description \\
\hline 1 & $\begin{array}{l}\text { Technology } \\
\text { acceptance }\end{array}$ & $*$ & $\begin{array}{l}\text { Perceptions of telemedicine } \\
\text { respondents benefiting the hospital } \\
\text { (Positive Perceptions) }\end{array}$ \\
\hline 2 & $\begin{array}{l}\text { Organization } \\
\text { Measurement }\end{array}$ & $*$ & $\begin{array}{l}\text { Organizations support to implement } \\
\text { telemedicine (Support) }\end{array}$ \\
\hline 3 & $\begin{array}{l}\text { Business } \\
\text { environment }\end{array}$ & $*$ & $\begin{array}{l}\text { The business environment demands } \\
\text { hospitals / clinics to implement } \\
\text { telemedicine. (Challenge) }\end{array}$ \\
\hline 4 & $\begin{array}{l}\text { Communicati } \\
\text { channels }\end{array}$ & $*$ & $\begin{array}{l}\text { Communication channels are good } \\
\text { considered (Appreciation) }\end{array}$ \\
\hline 5 & $\begin{array}{l}\text { Adoption } \\
\text { telemedicine }\end{array}$ & $*$ & $\begin{array}{l}\text { Respondents think telemedicine is a } \\
\text { good idea (Positive perception) }\end{array}$ \\
\hline
\end{tabular}

\section{Hypothesis}

The used method in this study to analyze the data is moderate regression analysis (MRA) between the independent variable and the dependent variable and the moderating variable with the following equation:

TABLE III: REGRESSION EQUATIONS

\begin{tabular}{cc}
\multicolumn{2}{c}{ TABLE III: REGRESSION EQUATIONS } \\
\hline Model & $\mathrm{B}$ \\
\hline (Constant) & 0.434 \\
Technology acceptance & 1.857 \\
Organization & 1.131 \\
measurement & 0.762 \\
Business environment & 0.062 \\
Moderate1 & 0.067 \\
Moderate2 & 0.040 \\
Moderate3 & 1.187 \\
Moderate4 & \\
\hline
\end{tabular}

The regression equation is as follows:

$$
\begin{gathered}
\mathrm{Y}=a+b_{1} X_{1}+b_{2} X_{2}+b_{3} X_{3}+b_{4} X_{1} Z+b_{5} X_{2} Z+b_{6} X_{3 .} Z+b_{7} X_{3} . X_{2} \\
. X_{3 .} Z+e
\end{gathered}
$$

$\mathrm{Y}=0.434+1.857$ Technology acceptance +1.131 Organization measurement +0.762 Business environment + 0.062 Technology acceptance moderated by communication channel +0.067 Organization measurement moderated by communication channel +0.040 Business environment moderated by communication channel +1.187 Technology acceptance, organization measurement, business environment moderated by communication channel $+\mathrm{e}$

The $\mathrm{F}$ test is carried out to test the hypothesis and determine the effect of the independent variables simultaneously on the dependent variable. The results of the F test get the calculated $F$ value of 26,838 and at the sig. $<0.05$ means that the regression coefficient is significant, then $\mathrm{H} 4$ in this study is accepted. This can be interpreted that if the acceptance of technology, the size of the organization, the business environment increases simultaneously, the adoption of telemedicine in PPKM SMEC will also increase.

The $t$ test was conducted to determine the effect of the variable partially on the independent variable. The results of the $t$ test can be seen in the following table: 
TABLE IV: REGRESSION COEFFICIENT AND T TEST

\begin{tabular}{|c|c|c|c|c|}
\hline Variablee & $\mathrm{t}$ & Sig & B & Description \\
\hline $\mathrm{X} 1$ & 2.981 & .003 & 1.857 & H1 Accepted \\
\hline $\mathrm{X} 2$ & 1.517 & .131 & 1.131 & H2 Rejected \\
\hline $\mathrm{X} 3$ & 1.014 & .312 & .762 & H3 Rejected \\
\hline $\mathrm{X} 1 \mathrm{a}$ & 2.223 & $\begin{array}{c}0.02 \\
8\end{array}$ & 0.062 & H1a Accepted \\
\hline $\mathrm{X} 2 \mathrm{a}$ & 1.928 & $\begin{array}{c}0.05 \\
6\end{array}$ & 0.067 & H2a Rejected \\
\hline X3a & 1.236 & $\begin{array}{c}0.21 \\
9\end{array}$ & 0.040 & H3a Rejected \\
\hline $\mathrm{X} 4 \mathrm{a}$ & 0.361 & $\begin{array}{c}0.71 \\
9\end{array}$ & 1.187 & H4a Rejected \\
\hline $\begin{array}{c}\text { Variable } \\
\text { X1-X3 }\end{array}$ & $\begin{array}{c}f \\
26,838\end{array}$ & $\begin{array}{l}\text { Sig } \\
.000\end{array}$ & & $\begin{array}{c}\text { Ket } \\
\text { H4 Accepted }\end{array}$ \\
\hline $.750^{\mathrm{R}}$ & & \multicolumn{2}{|c|}{ Determination Coefficient } & \\
\hline
\end{tabular}

Based on the table the calculated Sig value is $0.000<0.05$, meaning that the regression coefficient is significant, then $\mathrm{H} 1$ and H1a are accepted, so it can be concluded that there is a significant influence between technology acceptance and partial telemedicine adoption, and communication channels moderate the effect of technology acceptance on telemedicine adoption. Partial.

The coefficient of determination test results showed the R2 value of 0.563 . Based on the table, it can be seen that the adoption of telemedicine is influenced by technology acceptance, organizational size, and business environment and communication channels by $56.3 \%$ while the rest is influenced by other factors outside the variables tested in this study.

\section{DISCUSSION RESPONDENT CHARACTERISTICS}

It is known that of the 154 respondents who were studied based on gender, it was found that female gender was a greater proportion than male employees. Most of the employees are in the age group of 20-30 years. Respondents at productive age tend to easily accept an innovation compared to older respondents. This can happen because younger workers tend to seek innovation information than older ones. The spearhead of telemedicine is medical personnel, from the characteristics of the respondents, medical personnel who are eye specialists are in the $>30$ years age category, who are in the late majority or laggards' group. So, it tends to be slow to adopt a telemedicine innovation.

Hypothesis 1: Technology acceptance has a positive effect on telemedicine adoption in PPKM SMEC, $\mathrm{H1}$ is accepted

Based on the results of the $\mathrm{H} 1$ test, it is successful to prove that there is a positive and significant influence between technology acceptance on telemedicine adoption at PPKM SMEC, where the sig. 0.003 is smaller than 0.05 with a coefficient value of 1.857 . This means that the acceptance of technology has a positive and significant effect on telemedicine adoption.

It is known that the mean value of the questionnaire for the technology acceptance variable is 123 and is in the high category. This means that according to respondents the technology acceptance to adopt telemedicine is quite high. The highest index is in telemedicine according to current needs and must be able to be tested first. This shows that PPKM SMEC is ready to receive telemedicine.

Rogers [3] suggests that there are five attributes of innovation that affect technology adoption, namely relative advantage, compatibility, complexity, Trialability, and Observability. For PPKM SMEC, if telemedicine technology can be tested first, it will increase the adoption of telemedicine.

\section{Hypothesis 1a: Communication channels moderate the role of technology in the adoption of telemedicine in PPKM SMEC, H1a is accepted}

Based on the results of $\mathrm{H} 2$ testing, it is successful to prove that the communication channel strengthens the effect of technology acceptance on telemedicine adoption in PPKM SMEC, where the value of Sig. 0.028 is smaller than 0.05 with a coefficient value of 0.062 . This means that the communication channel significantly strengthens the influence of technology acceptance on telemedicine adoption.

It is known that the average value for the communication channel variable is 120.7 in the high category. This means that according to respondents the communication channel plays a role in increasing technology acceptance of telemedicine adoption. The highest index is in the communicator using language that is easy to understand.

Communication channels play a major role in the persuasion stage, meaning that with good communication it will increase information at the thought level of potential users. This is what strengthens the effect of technology acceptance on telemedicine adoption in PPKM SMEC.

According to Rogers [3], the decision-making model consists of 5 stages, namely: Knowledge, Persuasion, Decision, Implementation, Confirmation. And the most influential stage in the diffusion of innovation is the persuasion stage. For PPKM SMEC with good communication channels it will increase technology acceptance in the adoption of telemedicine.

Hypothesis 2: Organization measurement provides a positive increase on telemedicine adoption but has no effect on PPKM SMEC, $\mathrm{H} 2$ is rejected

Based on $\mathrm{H} 2$ testing, it is not successful in proving the effect of organizational size on telemedicine adoption in PPKM SMEC, where the value is sig. 0.131 is greater than 0.05 with a coefficient value of 1.131 . This means that the size of the organization will provide a positive increase in telemedicine adoption but will not have a significant effect.

It is known that the average value of the organization measurement questionnaire is 120 , including the high category, meaning that the size of the PPKM-SMEC organization is good enough to implement telemedicine. The highest index is on the CEO supporting to implement telemedicine; however, the large influence of the late majority and laggards' groups has hampered telemedicine adoption in PPKM SMEC. Ophthalmologists who are > 40 years old tend to find it difficult to accept an innovation. They are more careful about the function of telemedicine and are more comfortable practicing meeting face-to-face with 
patients than using information technology, especially if the technology is difficult to use.

Rogers [3] explains that the laggards' group is the last group to adopt innovations, they are more traditional in nature, and are reluctant to try new things. When this group adopts an innovation, most people actually have switched to adopting other innovations so that this group is considered out of date. For PPKM-SMEC, the influence of the laggard group is still high so that the adoption of telemedicine has not been optimal.

Hypothesis 2a: Communication channels do not moderate the role of the organization in the adoption of telemedicine in PPKM SMEC, H2a is rejected

Based on the results of $\mathrm{H} 2 \mathrm{a}$ testing, it does not prove that the communication channel strengthens the effect of organizational size on telemedicine adoption in PPKM SMEC, where the value is sig. 0.056 is greater than 0.05 with a coefficient value of 0.067 . This means that the communication channel provides a positive increase in telemedicine adoption but does not have a significant effect.

It is known that the average value of the communication channel variable is 120.71 , including the high category. In addition to language that is easy to understand, respondents also answered that the right channel of communication is interpersonal communication. Although the average value of communication channels is high, it does not have a significant effect on the effect of organizational size on telemedicine adoption, this is due to the influence of ophthalmologists at PPKM SMEC who tend to be in the late major or laggards' group which is still quite high.

However, the existing PPKM-SMEC communication channels have not been able to influence the size of the organization towards telemedicine adoption. So that in the perception process, ophthalmologists do not fully agree that telemedicine can be used for practice [11].

Hypothesis 3: The business environment does not have an influence on telemedicine adoption in PPKM SMEC, $\mathrm{H3}$ is rejected

Based on the results of the $\mathrm{H} 3$ test, it is not successful in proving the effect of the business environment on telemedicine adoption, where the value is sig. 0.312 is greater than 0.05 with a coefficient value of 0.762 , which means that the business environment will provide a positive increase in telemedicine adoption but does not have a significant effect.

It is known that the average value of the business environment variable is 125 , which is in the high category, meaning that the business environment in PPKM SMEC is supportive for telemedicine adoption. The highest index is in the statement that the government must provide regulations on the development of telemedicine, this means that most respondents consider regulations there is currently no use for telemedicine.

It is probable that telemedicine users, namely ophthalmologists or eye subspecialists, really consider telemedicine-related regulations, considering the data security of telemedicine users. So that this is the obstacle to the adoption of telemedicine.
This is in line with what Hameed [12] stated that the environment is one of the factors that influence technology adoption. In the business environment at PPKM SMEC, there are concerns among ophthalmologists and eye subspecialists to use telemedicine because of the unclear regulations governing the implementation of telemedicine.

Hypothesis 3a: Communication Channels do not moderate the role of the business environment on telemedicine adoption in PPKM Eye Hospital SMEC, H3a is rejected

Based on the results of the $\mathrm{H} 3 \mathrm{a}$ test, it does not prove that the communication channel increases the influence of the telemedicine adoption business environment in PPKMSMEC, where the value is sig. 0.219 is greater than 0.05 with a coefficient value of 0.040 . This means that the business environment provides a positive increase in telemedicine adoption, but it does not have a significant effect. One of the factors that play a role in the adoption of telemedicine is the pressure from business competitors so that the higher the competitiveness of telemedicine means the higher the willingness to adopt telemedicine.

It is known that the average value of the communication channel variable is 120.71 . Although the average value of communication channels is high, it does not have a significant effect on the influence of the business environment on telemedicine adoption, this can be caused by communicators who have not mastered the audience's psychology. Most of the ophthalmologists and ophthalmologists have not used telemedicine because they are still considering telemedicinerelated regulations. So that the adoption of telemedicine has not been fully implemented.

Hypothesis 4: Technology acceptance, organization measurement, business environment simultaneously has a positive effect on telemedicine adoption in PPKM SMEC, H4 is accepted

Based on the results of $\mathrm{H} 4$ test, it is successful to prove there is a positive and significant influence between technology acceptance, organization measurement, and business environment simultaneously on telemedicine adoption in PPKM SMEC. Where the sig. 0.000 is less than 0.05 . This can be interpreted that if technology acceptance, organization measurement, and business environment simultaneously increase, the adoption of telemedicine will also increase.

This is in line with the TOE Framework proposed by Tornatzky and Fleischer [7] that technology, organization and the environment are factors that influence the decision to adopt an innovation. The technology element describes the technological conditions that are relevant to the company such as: availability, characteristics and technology maturity, readiness of the equipment that has been installed in the company. Organizational elements refer to the measurement of the organization in detail such as the scope, size of the organization, and managerial structure. While the environmental element refers to the place, location, and conditions in which the company does business such as 
competitors and business partners as well as government policies.

The TOE model sees the technology adoption strategy as being above the context that influences it, this theory suggests that adoption is influenced by technological developments, organizational conditions, and the industrial environment [13]. For PPKM SMEC, increasing technology acceptance, organizational size, and business environment will increase telemedicine adoption [13].

\section{Hypothesis 4a: Communication channels moderate technology acceptance, organization measurement, business environment simultaneously has a positive effect on telemedicine adoption in PPKM SMEC, H4 is rejected}

Based on the results of the H4a test, it is not successful in proving that the communication channel strengthens the relationship between technology acceptance, organization measurement, and the business environment on telemedicine adoption. Where the sig. 0.719 is greater than 0.05 with a coefficient value of 1.187 , which means the communication channel provides a positive increase in the effect of technology acceptance, organization measurement, business environment simultaneously but not significantly.

It is known that the average value of the communication channel variable is 120.71 . Although the average value of communication channels is high, it does not have a significant effect on the simultaneous influence between technology acceptance, organizational size, and business environment on telemedicine adoption. This can be caused by inconsistent and continuous delivery of information in providing telemedicine information, as well as the clarity of information conveyed by communicators. Most of the ophthalmologists and eye subspecialists have not used telemedicine because they still do not know in more detail about the telemedicine system. So that the adoption of telemedicine has not been fully implemented.

In the innovation decision-making model in the first stage, knowledge is influenced by socioeconomic characteristics, personality, and communicator behavior. For PPKM SMEC, there are doctors who have not received information about telemedicine so that at the persuasion stage doctors refuse to use telemedicine because they do not benefit from using telemedicine due to lack of information, it can also be caused by the character of the doctor who is difficult to accept changes or is in the laggards category [3].

\section{RESEARCH FINDING}

Communication channels increase the role of technology on telemedicine adoption, communication increases technology acceptance on telemedicine adoption at PPKM SMEC. The most influential factor is technology acceptance on telemedicine adoption. Based on this, the researcher found that the telemedicine adoption process that is most concerned with is the technology aspect, and how an innovation is delivered, in this case the communication channel also plays a very important role in the innovation adoption process, telemedicine is an innovation because it is an idea or method in the form of a recently adopted project. by a person or organization, and telemedicine is something new in the field of medicine, including the PPKM SMEC where the interaction between patients and doctors is linked by information technology.

\section{CONCLUSIONS, IMPLICATIONS AND SUGGESTIONS}

\section{A. Conclusions}

Technology acceptance has a positive and significant effect on telemedicine adoption in PPKM-SMEC, and is strengthened by communication channels. While the size of the organization and the business environment did not significantly influence the adoption of telemedicine, neither was this relationship influenced by the communication channel. Taken together, technology acceptance, organizational size and business environment significantly influence telemedicine adoption. This means that the characteristics of technology are very influential on the adoption of telemedicine in PPKM SMEC, the characteristics of technology consist of relative advantage, compatibility, complexity, trialability, and observability.

\section{B. Managerial Implications}

Based on the obtained research results, the efforts that can be made by the management of PPKM-SMEC are as follows:

\section{Technology acceptance}

To increase acceptance of party technology. Management must pay attention to the benefits of using telemedicine, every doctor or employee who will use telemedicine is given an understanding of how much telemedicine benefits for patients and hospitals. The ease of technology used, and testing before it is implemented in all branches.

\section{Organization Measurement}

Based on this study, the size of the organization has no effect on telemedicine adoption, so it is necessary to study the decision making to use telemedicine, which can be in the form of authority with an approach to doctors through interpersonal communication.

The CEO supports the implementation of telemedicine, but the large influence of ophthalmologists who are mostly in the laggard category has made the adoption of telemedicine in PPKM SMEC being slow. Specialist doctors tend to find it difficult to receive telemedicine because they do not directly examine the patient and do not trust the results of the telemedicine examination.

\section{Business Environment}

Based on this study, the business environment has no effect on telemedicine adoption, it is necessary to examine the level of knowledge of telemedicine users, namely ophthalmologists or eye subspecialists on regulations related to telemedicine, because it considers the regulation and data security of telemedicine users. With the clarity of the current regulations, it is possible for hospitals / clinics to implement telemedicine.

\section{Communication Channel}

Communication channels have a positive influence on technology acceptance, the most suitable method is interpersonal communication, PPKM management must pay attention to the credibility of the communicator, the context and content delivered, the clarity and continuity of information to potential telemedicine users. 


\section{Suggestion}

From the results of the analysis and conclusions, the researcher tries to make some suggestions:

1. Regarding the acceptance of technology, the research team advised the leadership to hold more frequent meetings with doctors using telemedicine to provide training on the use of telemedicine.

2. Conduct periodic evaluations on the technology used by paying attention to the aspects of ease, benefits, visible results, and the suitability of current technology.

3. Improving the communication by paying attention to the following aspects:

- The credibility of communicators in delivering telemedicine socialization to doctors.

- Telemedicine content is delivered during scientific seminars / discussions.

- Routinely socialize the use of telemedicine.

- Take a persuasive approach using interpersonal communication, direct communication or in small group discussions so doctors can easily receive telemedicine and are willing to use existing telemedicine.

\section{ACKNOWLEDGMENT}

The author would like to thank Dr. dr. Supriyantoro Sp.P MARS, Dr. Hasyim, SE, MM, M.Ed., Dr. Rokiah Kusumapradja SKM, MHA and Dr. MF. Arozzi Adhikara, SE., Ak., M.Si., CA as examiner of this research.

\section{REFERENCES}

[1] Bernier, F., \& Lord, O. The Physician, Telemedicine And Information And Communications Graphic design. 2015.

[2] Portnoy, J., Waller, M., \& Elliott, T. Telemedicine in the Era of COVID-19. Journal of Allergy and Clinical Immunology: In Practice, 2020.

[3] Rogers, E. M. Diffusion Of Innovation (fifth). The Free Press. 2003.

[4] Al-Rahmi, W. M., Yahaya, N., Aldraiweesh, A. A., Alamri, M. M., Aljarboa, N. A., Alturki, U., \& Aljeraiwi, A. A. Integrating Technology Acceptance Model with Innovation Diffusion Theory: An Empirical Investigation on Students' Intention to Use E-Learning Systems. IEEE Access, 2019.

[5] Miranda, M. Q., Farias, J. S., de Araújo Schwartz, C., \& de Almeida, J. P. L. Technology adoption in diffusion of innovations perspective: introduction of an ERP system in a non-profit organization. RAI Revista de Administração e Inovação, 2016.

[6] Kissi, J., Dai, B., Dogbe, C. S. K., Banahene, J., \& Ernest, O. Predictive factors of physicians' satisfaction with telemedicine services acceptance. Health Informatics Journal. 2019.

[7] Tornatzky, L., \& Fleischer, M. (1990). The process of technology innovation. Lexington: Lexington Books.

[8] Senge, P., Kleiner, A., Roberts, C., Ross, R., Roth, G. and Smith, B. (1999) The Dance of Change: The Challenges of Sustaining Momentum in Learning Organizations, New York: Doubleday/Currency).

[9] Zhu, K., \& Kraemer, K. (2005). Post-adoption variations in usage and value of e-business by organizations: Cross-country evidence from the retail industry. European Journal of Information Systems, 12, 61-84.

[10] Oliveira, T., Martins, M.F. (2011). Literature review of information technology adoption models at firm level. The Electronic Journal Information Systems Evaluation, 14(1): 110-121.

[11] Duncan, Robert B. "Characteristics of Organizational Environments and Perceived Environmental Uncertainty." Administrative Science Quarterly, vol. 17, no. 3, 1972, pp. 313-327. JSTOR, www.jstor.org/stable/2392145. Accessed 25 Apr. 2021.

[12] Abdul Hameed, Mumtaz \& Counsell, Steve \& Swift, Stephen. (2012). A conceptual model for the process of IT innovation adoption in organizations. Journal of Engineering and Technology Management. 29. 358-390. 10.1016/j.jengtecman.2012.03.007.
[13] Kowath, N., \& Choon, T. (2001) Determinants of website development: A study of electronic commerce in Singapore. Information \& Management, 39(3), 227-242.

[14]Yeo, V.C.S, Goh, S.K., \& Rezaei, S. (2017). Consumer experiences, attitude and behavioral intention toward online food delivery (OFD) services. Journal of Retailing and Consumer Services 35 (2017) 150162.

[15]Oliveira, T., Martins, M.F. (2011). Literature review of information technology adoption models at firm level. The Electronic Journal Information Systems Evaluation, 14(1): 110-121.

[16]Hasyim, H., \& Anindita, R.. Developing Conceptual Model for Online Shopping Attitude in Indonesia : Based on the Diffusion of Innovations Theory. International Journal of Economics, Commerce and Management, 2016. 